\title{
LÍQUENS DA ÁREA DE RESERVA DO PARQUE ESTADUAL DAS FONTES DO IPIRANGA
}

\author{
Lúcia Yoko Nagaoka (1) \\ Marcelo Pinto Marcelli (2)
}

RESUMO - O objetivo deste trabalho é verificar a alteração da flora liquenica do parque neste século através da comparação de material de herbário com aquele encontrado atualmente na área de reserva do parque. Apenas 9 das 38 espécies levantadas em herbário puderam ser encontradas atualmente, sendo que a maioria apresenta sinais evidentes de perda de vigor e poderão desaparecer em pouco tempo. Pseudoparmelia texana (Tuck.)Hale aparece nas coletas posteriores a 1973 sendo agora abundante sobre troncos nas áreas mais expostas.

Palavras-chaves: líquens, flora, São Paulo, alteração, poluição.

ABSTRACT - The Parque Estadual das Fontes do Ipiranga is within the urban area of the São Paulo city (São Paulo state, Brazil) and through the years has received air effluents from a smelter of the vicinity. The aim of this work is to verify the change of the park's lichen flora by comparison of the extant flora with that held at the SP herbarium. Only 9 species can be found nowadays. 7 of them are very rare and from youngless populations. Parmotrema tinctorum (Nyl.) Hale is rare. Pseudoparmelia texana (Tuck.)Hale appears in the collections after 1973 and is now abundant, covering great trunk extensions at exposed places.

Key words: lichens, flora, São Paulo, pollution. 


\section{Introdução}

O Parque Estadual das Fontes do Ipiranga está localizado na zona urbana no município de São Paulo ( $23^{\circ} 39^{\prime}$ 'S e $46^{\circ} 38^{\prime} \mathrm{W}$ ) numa altitude média de $800 \mathrm{~m}$ e seus 70,2ha correspondem atualmente a um dos últimos resquícios da Floresta Pluvial do Planalto. Foi reconhecido no início de 1893 e possui este nome porque nele encontram-se várias nascentes do Córrego do Ipiranga.

Ao longo dos an us esse parque tem sofrido alteração ambiental principalmente devida à poluição atmosférica causada pelo crescente grau de urbanização da região, bem como pela instalação de uma siderúrgica vizinha (Struffaldi-de Vuono et al., 1984; Struffaldi-de Vuono \& Marzolla, 1984).

Este trabalho visa um levantamento preliminar das espécies de líquens do parque, comparando taxa atualmente existentes com aqueles coletados anteriormente e que constam do acervo do Instituto de Botânica de São Paulo.

\section{Metodologia}

Foi realizado um levantamento de todo material coletado na reserva do Parque e depositado herbário do Instituto de Botânica (SP). Na medida do possível a identificação das espécies foi confirmada.

Paralelamente foram realizadas excursões para levantamento da flora liquênica atual da área de reserva.

As floras antiga e atual são comparadas em composição específica.

\section{Resultados e Discussōes}

O material depositado em SP (41 exemplares) consta principalmente de espécimens coletados entre 1821-1934 (30 espécimens de um número incerto de espécies) e 1960-1973 (9 espécies). O material é escasso, mau coletado, constituído em sua maioria de fragmentos muitas vezes impossíveis de identificação a nível específico ou mesmo genérico.

Nas coletas realizadas em 1987-1988 foram encontradas apenas 11 espécies, mas considerando que estas coletas constituíram a primeira amostragem sistemática da área e que quase todas as espécies existentes atualmente devem ter sido encontradas, fica claro que um grande número de espécies de líquens deve ter desaparecido da área no decorrer deste século.

Além disso, a maioria das espécies presentes atualmente podem ser consideradas raras na reserva, sendo encontradas sobre pouquíssimas árvores, em populações constituídas quase exclusivamente ou exclusivamente de indivíduos velhos. São, portanto, espécies em vias de desaparecimento, já que seu processo reprodutivo (produção de propágulos, dispersão ou estabelecimento) está evidentemente afetado.

Atualmente pode ser observado que, possivelmente devido à poluição causada pela presença de uma siderúrgica vizinha, a cobertura vegetal da área de reserva do parque mostra evidentes sinais de degradação, com a presença de 
muitas árvores mortas, o que evidentemente altera a abundância específica relativa dos hospedeiros e o microclima interno à mata.

Das espécies coletadas em 1821-1934, apenas Parmotrema tinctorum (Nyl.)Hale, foi recoletada em 1987-88, sendo atualmente rara.

Pseudoparmelia texana (Tuck.)Hale é a única espécie relativamente abundante hoje em dia, podendo ser encontrada em muitas árvores de locais abertos como trilhas e borda da mata e muitas vezes cobre grandes extensões dos troncos das árvores isoladas. Essa espécie é tão comum que se estranha sua ausência de coletas anteriores a 1973 (mesmo em relação às áreas de visitação do parque) e é possível que se tenha tornado abundante apenas nas últimas décadas, com o aumento da poluição do ar.

Pseudoparmelia texana é uma espécie heliófila naturalmente encontrada em ramos finos e galhos na Mata Atlântica. A diminuição da competição pela eliminação de espécies aliada a abertura de ruas e clareiras e uma possivelmente alta tolerância à poluição do ar deve explicar o sucesso atual dessa espécie na área em estudo.

Abaixo são relacionados todos os espécimens já coletados na área do parque e depositados no herbário do Instituto de Botânica de São Paulo (SP), jưntamente com o número de herbário e ano de coleta. São fornecidos o nome atual (quando possível devido ao estado do material) mais o constante da etiqueta do herbário. Um asterisco (*) precede os nomes sem possibilidade de confirmação e. nesse caso, apenas é fornecido o nome da etiqueta.

Heterodermia sp., como Anapatychia (SP 17788, 1922)

Heterodermia leucomela (L.)poelt, como Anaptychia leucomelaena (SP 34072, 1921)

* Arthonia rubella Nyl. (SP 34065, 1921)

Bacidia millegrana (Tayl.)A. Zahalb. (SP 34066, 1921)

* Candelaria concolor (SP 34062, 1921)

Cladonia subradiata (Vainio)Sandst. (SP 50984, 1960)

Cladonia sp. (SP 158588, 1987; SP 158592, 1987)

* Cladonia sp. (SP 34305, 1934)

Coenogonium sp. (SP 34301, 1921)

Diploschistes sp. (SP 158591, 1988)

Glyphis sp., como Glyphis (SP 17787, 1921)

Graphis sp. (34300, 1921)

Gyalectidium rotuliforme Mull.Arg., como Myxodiction coffeae Mull.Arg. (SP 34213, 1883)

Herpothallon sanguineum (Sw.)Tobler, como Chiodecton sanguineum (Sw.)Vainio (SP 34074, 1821; SP 5857, 1921?; SP 100141, 1960; SP 100560, 1965; SP 100839, 1973)

Hypotrachyna sp (SP 158584, 1988; SP 158585, 1988)

Lecidea russula Ach. (SP 34060, 1921)

* Lepra citrina Ach. (SP 34061, 1921)

Letruitia dominguensis (Pers.)Haffel \& Bell., como Bombyliospora domin- 
guensis (Pers.)Zahib. (SP 34063, 1821)

* Parmelia meizóspora Nyl. (SP 34070, 1921)

Parmotrema abnuens (Nyl.)Hale, como Parmelia abnuens Nyl. (SP 34076, 1922)

Parmotrema crinitum (Ach.)Hale, como Parmelia catharinensis Arg. (SP 34068, 1922)

Parmotrema reticulatum (Tayl.)Hale, como Parmelia reticulata Tayl. (SP 100845, 1973)

Parmotrema tinctorum (Nyl.)Hale (SP 158582, 1987), e como Parmelia tinctorum Nyl. (SP 34078, 1921)

Parmotrema sp. (SP 34308, 1921; SP 100534, 1967; SP 158581, 1987;

SP 158583, 1987; SP 158593, 1987)

* Physcia aipolina Ach. (SP 34064, 1891)

Pseudocyphellaria sp. (SP 34309, 1920)

Pseudoparmelia texana (Tuck.)Hale (SP 158577, 1987; SP 158578. 1987; SP 158579. 1988; SP 158580, 1987), e como Parmelia texana Tuck. (SP 100849, 1973; SP 100861, 1973)

Ramalina geniculata Nyl.? (SP 34077, 1921)

Ramalina sorediantha Nyl.? (SP 34071, 1921)

Ramalina yemensis (Ach.)Nyl. (SP 34075, 1921)

Ramalina sp. (SP 17293, 1921; SP 100162, 1960; SP 100557, 1961;

SP 158587,1988 )

* Teloschistes exilis (Michx.) (SP 34069, 1921)

Thelotrema clandestinum Fée (SP 158596, 1988)

Usnea sp. (SP 158589, 1987; SP 158590, 1987)

Physciaceae (SP 158586, 1987)

Thelotremaceae (SP 158594, 1988; SP 158595, 1988)

? - SEM POSSIBILIDADE DE IDENTIFICAÇÃO (SP 17784, ?; SP 177295, 1921; SP 17295, 1922; SP 100536, 1967)

\section{Referências Bibliográficas}

STRUFFALDI-DE VUONO, Y., LOPES, M. J. M. S. \& DOMINGOS, M. 1984. Poluição atmosférica e elementos tóxicos na Reserva Biológica do Instituto de Botânica, São Paulo, SP. Revta. brasil. Bot. 7: 149-156.

STRUFFALDI-DE VUONO, Y. \& MARZOLLA. M. C. 1984. Decomposição da Serrapilheira nas proximidades de uma siderúrgica. Anais IV Congresso da Sociedade Botânica de São Paulo. 83-86. 